\title{
CLASSICAL MECHANICS AND CONTEMPORARY FUNDAMENTAL PHYSICAL RESEARCH*
}

\author{
Marián Ambrozy \\ College of International Business ISM Slovakia in Prešov \\ Miloš Lokajíček \\ Institute of Physics of the Czech Academy of Sciences \\ Michal Valčo \\ University of Presov in Presov \\ Greek Catholic Theological Faculty
}

\begin{abstract}
The contemporary scientific and technological progress builds on the accomplishments of classical mechanics from the 19th century when the so-called 'European scientific method and values' were accepted practically by the whole educated world. Most scientific results and conclusions were reached based on the causal ontological approach proposed in principle already by Plato's Socrates and developed further by Aristotle. Despite the late-modern paradigm shift in science (Galilei, Newton, etc.), the topicality of the ontological approach proposed by Aristotle (II. Analytics) remains. On the other hand, 19th and 20th century philosophers, mainly positivists such as Mach and Avenarius but also Schlick and Carnap, attempted to change this approach to unify scientific knowledge in accordance with an ideological, i.e. positivist outlook on reality. The authors place a special emphasis on the contribution of Rudolf Carnap and his interaction with Martin Heidegger. Three very different theories are applied to physical reality in the present: classical mechanics in the standard macroscopic realm, Copenhagen quantum mechanics in the microscopic realm, and special theory of reality in both realms in the case of systems consisting of objects having higher velocity values. Any explanation or description of transitions between different realms and theories had not been provided until now. Our paper describes the corresponding evolution in the modern period and identifies the underlying false philosophical assumptions and statements existing in today's scientific systems. We will then demonstrate that one common theory for all realms of reality may exist; one that will be based fully on Hamilton equations (only the law
\end{abstract}


offorce of Newton is to be generalized). Only time change of particle impulse (not directly acceleration) is to be determined by a corresponding force. All necessary characteristics of physical reality may be derived in such a case. Direct correlations of such physical approach to philosophy (ontology) will be drawn.

\section{NTRODUCTION}

Recently, numerous intellectuals active in the area of scientific knowledge have expressed critical standpoints to the contemporary state concerning the scientific approach to knowledge. Two main arguments have especially been mentioned. The mainstream journals are refusing to publish papers containing ideas that are not in agreement with generally accepted concepts even if these concepts are proven to be based on false or unwarranted assumptions. On the other side, enormous financial support from different grants has been given to authors of papers published in these journals even if the corresponding results have been in contradiction to papers presented elsewhere; the preferential treatment of such results has not been academically justified. It may be even possible to ask how the ample financial resources influence the specific presuppositions, outlook and methodology of research.

It is important to notice what happened in the 20th century and how these events lead to the present situation, which differs so fundamentally from that of two preceding centuries. At that time, the so-called 'European scientific method and values,' correlated with the results of classical physics' knowledge, were generally accepted even as basis for the formulation of ethical rules. In principle, it is necessary to ask what happened in the evolution of scientific knowledge since the end of the Middle Ages.

The change from the ontological approach advocated by Aristotle to the phenomenological one, apart from other important indicators, seems to relate to the phenomenological turn in philosophy. This, however, does not correspond to the development of the history of science. The phenomenological approach to quantum theory is explored by a phenomenology-oriented philosopher, Mamuka Dolidze (1999, 113), who states that in existential phenomenology "they are a logical extension of Bohr's position to the field of existential phenomenology." His approach rests in the reflection of theoretical physics by phenomenological philosophy. In what follows we will examine possible correlations and mutual dependences of this late-modern approach to scientific knowledge to the scientists' philosophical inclinations and metanarrative presuppositions. Our main focus will be on the time frame of the logical positivists. Our paper will offer a detailed analysis and critique of Rudolf Carnap's theory of constructing the world, discussing more broadly arguments for and against the phenomenological approach to science.

\section{SURVEY OF CONTEMPORARY SITUATION}

\section{The evolution of scientific knowledge in the modern period}

It is possible to say that the greatest scientific progress in history is represented 


\section{MARIÁN AMBROZY, MILOŠ LOKAJÍČEK, MICHAL VALČO}

by the classical physics. Its founders G. Galilei [1564-1642] and I. Newton [1643-1728] started from the causal ontological approach proposed by Socrates and developed further by Aristotle. In case of physics, the causal ontological approach, of course, may be connected to physicalism, which is the reduction of the metaphysical world into that which can be disclosed by the natural sciences. The given approach was based on the assumption that the world in which we live represents the basic source of our rational knowledge, without the addition of an extra element by a human being functioning as a cognitive framework. Some causal relations (assumptions) between different states of physical systems have been formulated on the basis of logical implication; consequences following on the basis of logical deduction have been then derived and tested.

The different possible principles of human knowledge were discussed mainly at the turn of Middle Ages and modern period and a parallel way (to classical one) developed, which resulted in the positivistic approach based only on phenomenological knowledge without testing any causal relations between subsequent phenomenal characteristics. The given approach was introduced in physics by Ludwig Boltzmann [1844-1906] in 1867 when the increase of entropy (phenomenological characteristics of a macroscopic system) was accepted as a basic physical law. Much greater changes in this direction then followed in the subsequent century.

Its application in physics can be found in the philosophy of Auguste Comte $(1868,29)$. This philosopher suggests that "the most inaccessible questions, - those of nature of beings, and the origin and purpose of phenomena, - should be the first to occur in a primitive state, while those which are really within our reach are regarded as almost unworthy of serious study." At the same time, Comte praised Fourier's research revealing the laws of thermal phenomena where their author did not try to reveal the nature of heat but studied only phenomena.

Ernst Mach [1838-1916] was the one who played a pivotal role in establishing the phenomenological approach in physics. His (1897) most important treatise is called "The Analysis of Sensations." Mach, who boldly anticipated the cosmological constant ë via the so-called Mach's principle, had advocated a purely phenomenological stance. According to Mach, the specificity of the laws governing quantum physics shows that the mechanistic and corpuscular view of the world cannot be maintained. His positivistic orientation is the thing that precludes him from being concerned with the essence, the carriers of the phenomena native to quantum physics. This essence resides outside the competence of a human being's ability to answer, thus beyond our cognitive abilities; it would be dominated by speculation, but nothing more precise. That is why the only viable position for a physicist is to be preoccupied by physical phenomena, and not by what is behind them, if there is anything at all. What exists is phenomena, not their individual essence. When physics talks about these essences - force, energy, etc. - the only thing they represent are fictions that help us understand the physical principles involved, and they do not exist in the sense of actual physical entities.

In his radicalism aimed against entities, Mach goes even a bit further. What is an entity? This is one of Mach's pivotal questions. Mach answers it with disregard for the ontological status of the subjective and the objective. He is not interested in whether 
there is something behind a phenomenon; he does not even care whether phenomena are something that exists independently of the self or emanate from the self; he does not hold any regard for the nature of that self. From this point of view, Mach et al. $(1959,30)$ formulates one of his most fundamental claims: an entity is a matrix of emotions. "Thus, perceptions, presentations, volitions, and emotions, in short, the whole inner and outer world, are put together, in combinations of varying evanescence and permanence, out of a small number of homogeneous elements. Usually, these elements are called sensations." Similar convictions were presented by Richard Avenarius [1843-1896] (1890). Notably, Mach had great influence on the development of young Einstein's ideas. The given trend continued then in the 20th century and brought a series of mistaking statements that are denoted now as main physical results. Some more details will be given in the next section.

\section{Phenomenological approach in the philosophy of science in the first half of the 20th century}

Mach's opinion further strengthened the phenomenological approach in physics. It was the aforementioned approach that functioned as an indicator of further philosophical notions which influenced the interpretation of the 20th century physics. It was identified as an inspiration in the manifesto of the Vienna Circle (1929) by Rudolf Carnap [1891-1970], Hans Hahn [1879-1934], and Otto Neurath [1882-1945]. This manifesto characterized the scientific understanding of the world not just as being empirical, but positivistic as well. It is an understanding based on that, which is immediately given. For one's own logical analysis it is better to use a more robust tool such as the modern formal propositional logic than the subject-predicate logic of Aristotle. The opinions of the representatives of the Vienna Circle regarding ideal science were apparently influenced by Auguste Comte. The hierarchical structure was as follows - emotions and thoughts of the subject, physical object, the contents of other minds, and social structures. Ernst Mach influenced the Vienna Circle by his phenomenalism and subjectivism.

Logical positivists were proud adherents of Mach. They even considered axiomatisation of physics similar to authors of Hilbert's program in mathematics. Logical positivists thanked Hemholtz and Mach for relativizing the terms time and space, and undermining the term causality (Hahn et al. 1973, 316). Positivists never defined the boundary between macro world and micro world.

Although the language of mathematics is the language of natural science, one must be aware of the risk of making a mistake by incorrect conclusions from consistent and elegant mathematically formulated physical theories. The above mentioned is also one of the reasons why mathematical realia are often related to physical theories.

Rudolf Carnap, one of the founders of positivism, formulated several influential opinions on the methodology and philosophy of science that had a direct impact on $20^{\text {th }}$ century physics. As one of the most agile members of the Vienna Group, Carnap defended the principle according to which a statement was meaningful only if it was a tautology, or it was verifiable. It is known that protocol sentences represent empirically verifiable data which are subsequently verified. Later, Carnap changed his criterion. Instead of 
a generally acceptable verification - the definitive decision about the validity or invalidity of a statement - he introduced the term confirmability. A sentence was confirmable if the observational statements contributed to its confirmation. Only protocol sentences were immediately verifiable (Carnap 1932, 215-228). Carnap negated the semantic criterion of the meaningfulness of the sentences of a language. Primarily, physics is the one that is evolving and cannot be definitively confirmable; therefore, the criterion of verification is replaced by confirmability. In case a law cannot be verified, it can be tested by means of testing its individual constituents that have been verified beforehand. "If in the continued series of such testing experiments no negative instance is found but the number of positive instances increases, then our confidence in the law will grow step by step. Thus, instead of verification, we may speak here of gradually increasing confirmation of the law" (Carnap 1936, 425).

This kind of criticism may be applicable to physics. As Schuster $(2011,115)$ stated, the physical sentence which goes as follows, "In the interior of an electron, there is a nucleus that does not externally manifest itself in any way," would not bear any meaning for positivists because it could not be empirically tested. The mentioned criterion of a sentence's meaningfulness was criticized by Ingarden and Quine as well. The said positivists' standpoints negatively influenced the development of physics in the 1930s. The discovery of subatomic particles of electrons and protons led to a new approach.

Let us take a closer look at the relevant aspects of the philosophy of Rudolf Carnap. In our case it will be a reflection of selected aspects of his work from the period of cooperation with the Vienna Circle, as well as the period in which he dealt with semantics. True, it cannot be said that the opinions of other logical positivists from the Vienna Circle were identical to those of Rudolf Carnap. As Otto Neurath put it, it was Carnap who most developed the empiricism of the Vienna Circle. Although The Scientific Conception of the World: The Vienna Circle (1929) received little attention in its time, the manifesto was still a part of logical empiricism. The manifesto was written by Rudolf Carnap and Otto Neurath.

The manifesto fully reflects Carnap's views, with the exception of the leftist social tone. Some thoughts of the text in question have direct correlations with the situation in physics at that time. The authors reject the depths in science, claiming that everything is on the surface. They claim affinity with the sophists, reiterating that man is the measure of all things. Their (Hahn et al. 1973,312) expression on causality in the emerging quantum mechanics is significant: "following the quantum theory there is even doubt whether the concept of strictly causal lawfulness is applicable to phenomena in very small space-time regions." Wittgenstein, whose manifesto was mentioned in good connotations, reproaches the text's essence as 'Großsprecherei.' As Fiala $(2006,24)$ points out, the thorough and honest authors of the manifesto later gave up some of the concepts in the manifesto. Carnap (1928) also shares similar views in The Logical Structure of the World. Mach and Avenarius provide a source of inspiration to Carnap in this period. Carnap intends to build a conceptual network of the world on a phenomenalistic basis, building on the elementary experiences of constructing specific entities in a three-dimensional world. The outer world is a logical construction of sensory 
data. Here, Carnap is fully adhering on positivism. The work of this prominent representativeof the Vienna Circle influenced the development of the newly-emerging quantum mechanics. Obviously, not everyone was ready to accept these views. Quine, for example, believes that it is possible to compare our construction of the world with sensory data, but not to directly infer the nature of the world from our sensory data.

In this sense we may ask to what extent is the principle of verification, discussed by Carnap and other members of the Vienna Circle, influenced by Ludwig Wittgenstein [1889-1951]. Carnap $(1963,45)$ himself explicitly referred to him in his autobiography stating, "this principle says first, that the meaning of a sentence is meaningful if and only if it is in principle verifiable, that is, if there are possible, not necessarily actual, circumstances which, if they did occur, would definitely establish the truth of the sentence." This standpoint has been observed in works of pragmatists. Problems arose when a single indisputably protocol sentence was to be made; an elementary sentence could not be made either by Wittgenstein or by Carnap or Neurath (Schuster 2011, 113-134).

Let us try to evaluate the period in which our thinker dealt with syntax and gradually moved from purely positivist attitudes to physicalist views. Despite our critical assessment, Carnap, of course, also has a lasting merit in the history of science and philosophy. It must be acknowledged that at a conference in Prague in 1934, in the text titled The Method of Logical Analysis, Carnap fundamentally manifested the distinctive natures of psychology and philosophy, separating psychology as a distinct science from philosophy. Similarly, Husserl in 1900 distinguished logic from psychology. Despite the commendable distinction between psychology and philosophy, Carnap determined the content of philosophy in a very austere manner - logically analysing the language, especially the language of science. In Carnap's point of view, sentences are either tautologies, contradictions, or neutrals if they are to make sense. During his work in Vienna and later in Prague, Carnap considered the true sense of philosophy to be a logical-syntactic analysis of the language. The philosopher "originally believed that all meaningful utterances about physical reality are defined by [linguistic] terms or through experience, in accordance with a strong version of the verification process - the meaning of the statement is given by the way it is verified" (Mihina 2006, p. 251). Carnap's views in this period were certainly best developed in his The Logical Syntax of Language [Logische Syntax der Sprache] (1934a). All problems of philosophy are perceived as reducible to the logical syntax of language. One of the sources of inspiration for Carnap in this period were some conclusions drawn by Hilbert in his philosophy of mathematics. These inspirations were fully reflected in Carnap's understanding of the fundamentals of physical science. As he $(1934 b, 18)$ says in the text "On the Character of Philosophical Problems":

The problems of the foundations of physics are the questions of the syntax of physical language: the problem of the verification of physical laws is the question concerning the syntactic deductive coherence between the physical laws (i.e. general propositions of a certain form) and the protocol propositions (singular propositions of a certain form); the problem of induction 
is the question whether and which transformations rules lead from protocol propositions to laws.

Similarly, the problem of finitude or infinity of time and space is perceived as reducible to the questions of syntactical transformation rules with relationships to numbers, which appear in the physical propositions. Carnap considers the problem of causality a question of the syntactical structure of the physical laws. He refers here to unique or probability functions and the completeness of the systems of these laws, which points to the dilemma of determinism vs. indeterminism. Remarkably, the question of the foundation of biology has shown a line of influence through Comte, as Carnap considered the language of biologists only a part of physical language.

It is revealing to notice how Carnap in the quoted text, having been evidently inspired by Mach, approached the question of reality through the prism of the syntax of the language of science. The following theorems are presented as thesis and antithesis: A thing is a complex of sensations; and A thing is a complex of atoms. $\mathrm{He}(1934 \mathrm{~b}, 16)$ attempts to show that both statements can be broken down into sentences, since "every proposition in which a thing-name occurs, is equal to content." Referring to positivism, he adds: "with a class of propositions in which no-thing names but sensations-names occur;" and in case of realism: "with a proposition, in which no names of space-time coordinates and physical functions occur." Carnap argues that they do not contradict each other, because they can be transformed in more than one way with equal content.

Carnap considers the question "What is thing?" a pseudo-problem. He argues here that all philosophical statements are ready for discussion only when we formulate them as statements of the syntax of the language of science. Thus, at the early stage of his philosophical work, Carnap considered the ontological question to be a pseudoproblem, a matter of the syntax of the language. He (1934b, 8) also looks at the construction of science through logical syntax. "To construct science means to construct a system of propositions which stand in certain fundamental coherence with one another."

After the publication of the works of Tarski, Carnap forsook the idea of focusing purely on logical syntax and began to take into account semantics. Carnap's $(1936,456)$ verificationism is based on confirmability, as stated in "Testability and Meaning": "A sentence $\mathrm{S}$ is called confirmable (or completely confirmable, or incompletely confirmable), if the confirmation of $\mathrm{S}$ is reducible (or completely reducible, or incompletely reducible, respectively) to that of a class of observable predicates." In the above-mentioned text, he $(1936,464)$ had already revised some of his previous opinions, for example, that every sentence of the language of science could be translated into a sentence about perceptions. Carnap here no longer held the view of the unlimited reducibility of the language of science to the language of perception with reversed translation, gradually moderating his originally radical positions.

However, in his "Foundation of Logic and Mathematics" Carnap (1939) still avoids the causal-ontological principle. He notices an increased degree of formalization in physics. He claims that physicists have increasingly given up on the requirement to 
intuitively understand axioms, theorems, and abstract terms. Carnap disagrees with those philosophical interpretations that speak about mere formalistic constructions when referring to some physical theories. Carnap $(1939,68)$ defends the inexplicability and intuitive incomprehensibility of the notions of contemporary physical theories claiming that such was the case already in classical physics. "If we demand from the modern physicist an answer to the question what he means by the symbol $\psi$ of his calculus, and are astonished that he cannot give an answer, we ought to realize that the situation was already the same in classical physics." On the other hand, Carnap is in his "Foundation of Logic and Mathematic" already aware of the important role of semantics in the methodology of science, especially in the interpretation of formal systems, e.g. axiomatic systems in physics (Tondl 1968, 13).

Since the mid-1930s Carnap distinguished two kinds of probability. In physical sciences, probability is based on the mathematical calculus of probability; the probability of hypotheses, on the other hand, speaks of the degree of confirmation of some theory (the problem is addressed by several authors, for example Mach (2009)). We find the same type of argumentation in Carnap's (1945) article "The Two Concepts of Probability," in which he argues mainly with Jeffreys and Keynes.

Carnap's most distinctive contribution to the period of strict positivism is when he developed a phenomenalistic philosophy of physics under the influence of Mach and Avenarius as well as selected theses from Wittgenstein's Tractatus. He corrected some of his own radicalism by moving to physicalist positions, where he reduced the philosophy of selected science to the syntactic analysis of the language of that science. Nevertheless, even during the period of his interest in syntax, Carnap remained far from the causal-ontological approach. Such a reductionist perception of philosophy impoverishes a theoretical physicist's aspirations to gain a holistic view of his discipline, because this reductionism causes one to miss "the experience of detecting and reaching dead ends, as well as the experience of conceptual confusions and their clarification and unravelling" (Maco 2018,280). The second consequence is to downplay the importance of reality by reducing it to the problem of the syntax of the language of science. It turns out that even in the period when he began to deal with semantics, Carnap did not identify with the causal-ontological principle in physics, advocating instead the inexplicability concepts and the intuitive inability to grasp them. Overall, Carnap did not change his phenomenalistic approach to physics in his frequent modifications of the concept of access to language and science, despite his gradual transition from positivism to physicalism.

Radek Schuster assumes that image invariance as a theory of language, found in Wittgenstein's treatise Tractatus logico-philosophicus, constitutes the basis for the creation of consequences in favour of verificationism. The logical image of a situation, a thought, is a meaningful sentence. Many philosophers and philosophical historians have believed verificationism to be an implicit part of Wittgenstein's Tractatus. In Hymers' $(2005,205-234)$ opinion, Wittgenstein advocated the notion of verificationism for a short period of time and because he was influenced by his respect towards Schlick, Wittgenstein's version of verificationism differed from that of positivism. It can be 
contested whether Wittgenstein truly advocated verificationism or not; however, it is a fact that his image isomorphism had a direct impact on the verificationist stance of logical positivists. In the 1920's and 1930's they proclaimed themselves to be the creators of the ideal of science, and their notions directly influenced many physicists during the first half of the 20th century. "In physics it is more difficult to shun the suspected entities because the language of physics serves for the communication of reports and predictions and hence cannot be taken as a mere calculus" (Carnap 1950, 20). According to Carnap, a physicist can proclaim a certain part of language as void of interpretation. Linguistic elements such as these are, according to Carnap, compatible with empiricism. The question of categorizing a term into categories such as scientific term, metaphysical term, or empirical term, differs from the question concerning the reality of the objective world. "To be real in the scientific sense means to be an element of the system" (Carnap 1950, 22). One's acceptance of objective language does not automatically involve one's conviction pertaining to the reality of objects. For Carnap, these questions were inappropriately formulated. His arguments are that in the empirical questions about the locality of an entity with respect to its coordinates in the four spatial dimensions of a physical object, it is meaningful to venture an answer; however, to ask about the reality of physical space and time is to ask a question, which is beyond science. Carnap believed that the question of physical time and space is really a pseudo-question. In this sense, the question could be postulated from a more pragmatic point of view, i.e. whether it is fruitful or favourable to ask such a question, or whether such forms can be established in language (which is, according to Carnap, a matter of choice). What we come across most often, by the way, is "a concept that understands time as a privative mode of eternity" (Sucharek 2006, p. 642).

The non-cognitive character of the questions, termed by Carnap as external, was pointed out by Moritz Schlick [1882-1936], the student and successor of Ernst Mach. The positivistic notion - only what is given exists - Schlick $(1948,466-477)$ transformed into the statement that problem of reality of the outside world's is a meaningless question. Words that cannot be otherwise defined are accepted as being given. They cannot be exchanged for definable statements; therefore, determining the conditions for the meaningfulness of a statement is finally postulated in that which is being given. Planck - a suitable representative of physics - agrees with positivists in that a source of knowledge independent of sensory perception does not exist. The meaning of statements about physical objects is understood by Schlick $(1948,466-477)$ as the possibility of their verification which is not rare. The problem of the reality of the world is answered by Schlick as follows - existence is not a real predicate. Claiming the reality of a feeling or emotion, and the reality of a physical object is one and the same proposition. According to Schlick, however, a statement about reality can be explained only based on its connection with sensory perception. While Schlick claims that an empirical world does exist, he regarded the metaphysical hypothesis accepting the transcendental exterior world as pointless. The separation of the transcendental exterior real world from the empirical world is seen by Schlick as nonsensical. The meaning of phrases such as 'absolute reality' or 'transcendental existence' does not mean an indeterminate claim to 
their facticity, but rather a statement about the emotional state of the one who states. The existence of the external world is not disputed; the statements concerning objects may be changed to equivalent sentences concerning the emergence of emotions (Schlick 1948, 466-477). To contest or affirm the transcendental real world is, in Schlick's view, absurd. The phenomenological stance of Carnap's - earlier and later - work, along with Schlick's scholarly view have established an etalon in the methodology of the philosophy of science. The phenomenological approach was assumed by other philosophers who were especially oriented towards logical positivism. "Any unverifiable statement should be considered a 'pseudo-statement' whose meaningfulness can only be established on the emotional level. Hence the philosophers' new task is to organise rather than develop knowledge, as well as the overall uneasiness among 'genuine scientists' to fully engage in ethical and/or metaphysical discourses" (Valčo 2017, 22).

One may say, in defence of logical positivists, that their intention was to give meaningful content to philosophical reflection to prevent it from becoming a dysfunctional collection of useless utterances. Philosophy was thus left with a single sphere of competence - the logical analysis of language.

The influence of philosophy on scientists in the first half of the 20th century

One can only agree with Zouhar's $(2014,202)$ claim that: ,if physics is not done by philosophers (as philosophers, not philosophers as physicists), it will yield much better results." Despite his assertion, the influence of philosophy on 20th century physics can still be observed and discussed. For example, Max Born [1882-1970] said that theoretical physics is, in essence, philosophy. After all, it can be proven by the vagueness of many results of theoretical physicists.

Although the impact of positivism on Max Planck [1858-1947] is not evident, his enthusiasm for some of Comte's ideas is noticeable. Mach or Avenarius, on the other hand, did not belong among the philosophers Planck agreed with; quite the opposite, he was very critical towards them. Even though Planck (1991) discusses the manifestations of the materia as a sum of physical experiences, he emphasizes the reality of physical phenomena as being independent from sensory perception. Contrary to Mach, Planck advocated the reality of atoms.

Werner Heisenberg [1901-1976] is another physicist whose work exhibits traits of positivism. His (1978) criticism of Kant was partially justified because Kant wanted to incorporate several physical laws, such as the equality of action and reaction, the law of the conservation of mass, and even the law of gravity into his synthetic, a priori judgements. Heisenberg also criticized Kant's understanding of causality as an assertion that one event precedes another, which happens according to certain rules. From the point of view of the Copenhagen interpretation of quantum mechanics, not only did Heisenberg categorically dismiss the a priori character of the law of causality, he also claimed that causality, as understood by classical physics, cannot be applied to quantum mechanics. He also saw Einstein's reservations to the Copenhagen interpretation of quantum mechanics as emanating from the position of dogmatic realism. Heisenberg 
himself stated that Einstein's position stems from his assertion that physics describes nature as an accurate representation of reality and not as something that has been made up by human beings. He (1978) reminds us that quantum theory, especially in its form of the Copenhagen interpretation, allows for an explanation without this assertion. In this sense, Heisenberg anticipates Richard Rorty's [1931-2007] (1979) stance related to the falsification of the correspondence theory of knowledge. Rorty criticised the correspondence concepts of knowledge. He believed that the claim, according to which the statements of language correspond with reality and reflect it as a mirror, was just a historical illusion.

The analysis of the impact of philosophy on Niels Bohr [1885-1962] is also one of interest. Edgar Rubin [1886-1951], a phenomenology-oriented psychologist from the school of Gestalt psychology, influenced Bohm's work because his "discussions with Rubin have found their echo in Bohr's later concept of complementarity" (Grygar 2014, 35). Those discussions were aimed at borderline topics related to psychology and philosophy. Bohr was also influenced by a positivistically oriented Danish philosopher, Harald Høffding [1843-1931], who described the principle of complementarity in relation to psychological conditions (Grygar 2014, 25-76). Bohr, however, denounced the influence of Høffding, James, or Kierkegaard on his work, and only admitted to his inspiration by Edgar Rubin. It could be argued that Høffding was Bohr's teacher, and they had frequent scholarly discussions together. In spite of that, Bohr cannot be thought of as a philosopher. He was, however, influenced by philosophy in certain aspects of his theories.

The philosophical basis of Erwin Schrödinger [1887-1967] is a little different. It was the source of his conflict with the physicists from Copenhagen and Göttingen during the 1950's. The most notable conflict was the one with Born who thought that "Schrödinger's regressive trend towards classical pictures is just a matter of philosophical incapacity" (Bitbol 1995, 3). It is known that Schrödinger ascribed objective reality to waves, not particles, and did not interpret them in terms of probability; furthermore, he also rejected quantum leaps. He was also opposed to Kant's thing-initself, as well as Bohr's complementarity, to which he was quite sceptical. In a way similar to Descartes's attempt at differentiating between res cogitans and res extensa, Schrödinger differentiated between the apparatus and the object (Bitbol 1995, 24). However, in his "On the Behaviour of Atoms in Collisions" Bohr (1925, 142-157) proposed a corresponding probabilistic particle interpretation, which was shown later to be in full agreement with classical Hamilton equations.

Young Albert Einstein [1879-1955] was also under the philosophical influence of positivism, most notably the positivism of Ernst Mach. Later on, he assumed different ideological positions and tried to eliminate unpredictability. His basic conviction regarding the inner workings of nature was inclined towards the causal ontological approach. Nota bene, Einstein was aware of Hume's influence on the emergence of positivism and considered him to be a thinker who had contributed to the reduction of science into its phenomenological description. 


\section{Corresponding changes in the last century}

The earlier trend was then supported significantly by Niels Bohr (in 1913) when the basic physical law concerning atom structure was represented by two phenomenological postulates. However, the contemporary situation has been caused mainly by a further step taken by Bohr (1928, 580-591) when he added some quite arbitrarily chosen assumptions to Schrödinger equation and formed the Copenhagen quantum mechanics (CQM) in 1927. He deformed fully the physical interpretation of the solutions of given equation that were interpreted originally by Schrödinger in the standard classical sense (particle motions have been described with the help of corresponding solutions of Schrödinger equation - by the so-called expected values derived from corresponding amplitudes). It has been, however, assumed that the Schrödinger equation has not described classical properties exactly, which has been the case practically till now. However, as it was demonstrated in the end of the preceding century, the Schrödinger equation may be derived practically for the whole superposition set of the solutions of classical Hamilton equations. It has been only necessary to exclude the set of spiral solutions existing in Hamilton's case for attractive potential in addition to standardly considered elastic states (Ioannidou 1982, 453-458; Hoyer 2002, 1-252; Lokajíček 2007, 69-77).

\section{On the interpretations of quantum mechanics}

According to philosopher Peter Volek $(2011,372)$, the Copenhagen interpretation of quantum mechanics "leads to the renunciation of the existence of elementary particles as well as to an overall acceptance of reality as a whole where elementary particles occur as its non-independent and unreal aspects." In the spirit of such an interpretation, "such a statistical view is not about individual particles/planets and their individual trajectories in time" (Whitney 2015, 80). In this case, it is the matter of dismissing the causal ontological approach. If we choose to respect Chakravartty's differentiation of the properties of the subject of scientific theories into detection properties and auxiliary properties (the observable objects possess causally active properties, while nonobservable objects possess causally inactive - auxiliary - properties), then, according to Schmidt, we should relevantly accept the division of scientific realism into a) nonrestrictive scientific realism which considers detection properties and auxiliary properties as equal, b) ultra-restrictive scientific realism that only acknowledges objects with detection properties, c) restrictive scientific realism that allows for both types of properties; however, it regards detection properties as scientifically more relevant than other properties (Schmidt 2010, 643-651). In accordance with the aforementioned division of scientific realism, the Copenhagen interpretation of quantum mechanics resides in the position of non-restrictive scientific realism, while the causal ontological approach is compatible with the ultra-restrictive scientific realism.

It is known that other interpretations of quantum mechanics were created. Even Madelung came up with the hydrodynamic interpretation of the Schrödinger equation which was further expanded into the Broglie - Bohm interpretation. In this interpretation, a system of particles is partially described by the wave function expressed by the 
Schrödinger equation. The current location of a particle is described by an equation that expresses the velocity of particles in terms of the wave function (Karaba 2009). The development of the progression in the system of particles has a deterministic character, while the property of mechanics is non-locality. Bohm's way of solving the interpretation was developed in accordance with the reaction concerning the EPR paradox.

David Bohm [1917-1992] revised Schrödinger's equation so it would be explicable in classical terms; therefore, the equation gains on its complexity. Bohm described quantum potential as being strangely arbitrary. Bohmian mechanics attempts to more accurately explain the fact that characteristics of both waves and particles are present (Karaba 2009). This was already partially addressed by de Broglie. The movement of a particle going through one slit may be affected by a wave that is moving through both slits. The particles do not move towards the way where the waves disrupt one another; they move towards a place where they are strengthened by superposition. This was brought to attention by John Stuart Bell [1928-1990]. The dissolution of the interference, when we know through which slit the particle moved, is explained by the Bohmian interpretation as an interaction with another system via the collapse of the wave function. "Each particle will learn the arrangement of the whole system (the presence of the second slit) based on quantum potential" (Jelen 2018, 5).

As Jelen $(2018,5)$ calls to attention, this interpretation is, in the context of nonrelativistic quantum mechanics, "able to reproduce the usual results of quantum mechanics." As opposed to the Copenhagen interpretation of quantum mechanics, the classical interpretations seem to be much closer to the causal ontological approach in science. When considering the two most influential interpretations, the approach of physicists that interpret the phenomena of the micro world in a classical way simply seems much more rational and approachable when trying to maintain a stance in which causality and ontology dominates. On the other hand, the Copenhagen interpretation finally appears to be fully purposeful in the phenomenological approach to reality. There is a number of classical interpretations of quantum mechanics, such as Bopp's statistical interpretation, or the paleo classical interpretation (Schmelzer 2015, 179-211). In any case, in accordance with the refusal of the phenomenological approach in physics, we adhere to classical terminology and, in the domain of the micro world, we advocate the position that "an appropriate combination of trajectories, potentials, energies, and waves for developing the theory of micro phenomena was not found" (Sveènikov 1966, 126). We believe language and the tools of classical physics to be of pivotal importance. After the works of Ioannidou (1982, 453-458) and Hoyer (2002, 1-252) it became obvious that this interpretation is in discrepancy with Schrödinger's equation.

\section{Special theory of relativity and velocity increase}

The results of this theory have been based on the Lorentz transformation that has correlated the time with coordinates of any moving particles with the help of light velocity value cl. It has been then derived for any particle that its velocity relates to kinetic energy as 


$$
v=c_{l} \sqrt{1-\left(\frac{E_{0}}{E_{k i n}(v)+E_{0}}\right)}
$$

where $\mathbf{E}_{\mathbf{0}}=\mathbf{M}_{\mathbf{0}} \mathbf{C}_{\mathbf{L}}{ }^{2}$ represents an additional rest energy derived from inertial mass at zero velocity. It follows from the given formula that the velocity of any particle cannot exceed the given light velocity. The given equation has been derived on the basis of Lorentz transformation that has been based on the assumption that time unit is defined as the time corresponding to the unit track of light.

It means that the inertial mass is to increase with rising velocity, which differs significantly from the classical formula: $\mathbf{E}_{\text {KIN }}(\mathbf{v})=1 / 2 \mathbf{M V}^{2}$ where $\mathrm{m}$ is regarded to be constant. In the special relativity it holds

$$
m(v)=m_{0} \gamma(v), \gamma(v)=\frac{1}{\sqrt{1-\left(\frac{v}{c_{l}}\right)^{2}}}
$$

It follows from the given formula that the inertial mass must increase with increasing particle velocity; the light velocity is to represent then maximum possible velocity of any particle (inertial mass having reached infinite value). Even if the validity of the given formula has not been practically verified until now by comparison with experimental data (no corresponding data having being presented) its validity has been fully accepted after the increase of inertial mass with increasing velocity has been found experimentally already at lower velocity values; any concrete values have not been, however, practically available.

The increase of inertial mass may be, however, derived also in the framework of Hamilton equations. The time changes of particle impulses (not directly velocity changes) may be derived from the corresponding potentials if the results have not been limited by Newton's simplifying condition. One may say that in such a case these equations represent generalized classical physics (GCP), where the time dependence of individual characteristics differs significantly from those existing in original classical mechanics (CM).

In closed physical systems all solutions of Hamilton equations must conserve two basic quantities: total energy (the sum of kinetic and potential energies) and angular momentum vector. In GCP the impulse derivative is given by the force defined as space derivative of potential. The velocity dependence of kinetic energy differs then significantly from that derived in CM (when Newton's simplifying condition was applied to).

In the framework of GCP also some other different relations have been derived between physical characteristics. It is now also possible to derive quite new relations concerning the increase of inertial mass at different velocity values. 


\section{Reflection of the discussions on the nature of mathematics in the context of the given issue}

Carnap himself perceives mathematics to be in the service of the so-called real sciences. According to him, mathematics' formal, analytical phrases have no independent meaning. Carnap (1936) considers the question of whether the calculus of analytical sentences can be considered a science a minor issue, which belongs to the field of terminology and a consensus for conformance to contemporary language usage. From the point of view of logical positivism, the controversy over the nature of mathematics is interesting. Carnap's original starting point is logicism. In the discussion of the struggle for the essence of mathematics between intuitionism, formalism, and logicism, physics was mostly influenced by logicism and formalism. Hilbert's vision of axiomatizing mathematics had an inspiring effect on Schlick above others. "The first system of axioms of set theory was introduced by E. Zermelo (1908). The axiom scheme of replacement was invented and added to the Zermelo system by A. Fraenkel (1921)" (Bukovský 2011, 36). Hilbert also influenced Carnap's efforts to build a purely analytical theory of language structure. "Carnap tried to deal with the basic problems of logic and language theory on the level of syntax, that is to say, on the level of which language is considered as a formal structure and dealt with the axiomathic method" (Hintikka 1996, 167). He understood the basic concepts of logic as purely syntactic terms. His opinion on how mathematics is built says that logical conventionalism, that is the free choice of language rules within the syntax, known as the principle of tolerance, is valid. Hilbert also assumed a fundamental possibility of an axiomatic program in physics. Moritz Schlick belonged among those endorsing this notion. "Leibniz (1646 - 1716) is particularly inspiring for Schlick and his group in terms of reviving the older idea of the possible formation of mathesis universalis, a hypothetical universal science as a symbol of much broader efforts for a unified science" (Mihina 2006, p. 687). Schlick's notions of axiomatization of physics were not accepted in unison by logical positivists, but the idea of geometrization of physics found a response in some physicists, for example, in Einstein. "Hilbert set himself a goal to build a complete system of axioms in Mathematics but was stopped in his endeavour by the Incompleteness Theory formulated by Goedel" (Crumpei et al. 2016, 789). Certainly, the well-intentioned objective of Hilbert to build a unified structure of axiomatized mathematics, and prospectively also physics, has failed.

A significant contribution to the view of mathematics was made by Alan Turing. David Hilbert (1928) postulated in mathematics the so-called 'Entscheidungsproblem.' It is a question of whether there is any procedure that can decide whether or not a postulated statement in mathematics is decidable or not. The opinion that this is not the case was presented by Gödel. He assumed there were also undecidable questions. The problem was solved by Turing (1938) in "On Computable Numbers." Turing wondered if it was possible to bring each calculation to conclusion by using a computational algorithm. He divided this problem into concrete steps. He designed an abstract machine concept, the Turing machine. Algorithms are performed in a specified sequence of steps. Turing created the idea of a machine whose internal operation is variable so that 
it can perform all possible functions of the Turing machines. Turing thus proved that there are incalculable functions that cannot be mimicked by the logical operations of the Turing machine. Thus, mathematics contains principally undecidable problems. This conclusion was not favourable for Hilbert's program, nor for the optimistic visions of logical positivists.

Some aspects of the dispute over the nature of mathematical objects in the first half of the 20th century may be in favour of the causal-ontological approach. Here are some interesting realistic views of some mathematicians. For example, Bar-Hillel and Fraenkel perceive mathematical disciplines as those that examine truly existing structures. Even the well-known mathematician, Hermann Weyl, whose mathematical procedures were respected even by the physicist Paul Dirac, "felt a natural affinity for the Platonic approach, according to which mathematical entities are real and transcend the human creative process" (Barrow 2000, 250).

\section{THE PREFERABLE FUTURE WAY}

The immense success of classical physics was based (as already mentioned) on the causal ontological approach to knowledge proposed in principle by Socrates and developed by Aristotle. In Europe, the given approach was accepted in $13^{\text {th }}$ century from Islamic sciences and developed further based on a happy convergence of contemporary natural science and Christian approach to the world by Thomas Aquinas [1225-1274]. As it was analysed later to greater details by K. Popper [19021994] (in 1925) the given approach was based fundamentally on the falsification method. As Popper notes, each increase in the clarity of reasoning should be in itself intellectually valuable and the increase in exactness possesses a quality of the pragmatic as the tool for attaining a certain goal. It should be not true that the natural sciences are only inductive. Philosophy must refute this mistake and science must, in return, express the difference between science and pseudoscience.

This is the bone of contention. Science chooses either verifiability or falsifiability, thus induction can be omitted! While verifiability is a conclusion that is inductive in nature - we ask whether something is the truth and we compare it to reality - the process of falsification is something different. Different statements concerning the world evolution may be derived from world observation and formulated on the basis of logical induction. However, such statements may lead to wrong conclusions. It is necessary to derive all possible deductions from them and to confront these deductions with the corresponding reality (if it should be possible). If one finds any contradiction, the original statement (or a combination of statements) must be declared as invalid (false); and this piece of "negative" knowledge is denoted as certain. Such a falsified statement (or a corresponding combination of them) is then declared as intolerable when the truth about our world must be respected. The results of classical physics were based on corresponding unfalsified statements only. If we are unable to falsify such theories, they will remain theories forever.A statement which is not falsifiable is metaphysical, 
yet not nonsensical as also logical positivists claimed (Viceník 1999, 158-166). That is why it is said that science is a network of hypotheses, a fabric of implications.

Such non-falsified theories do not claim to be true. We can, however, justify the reason for our choosing these theories over the competing ones. Scientific advancement does not reside only in the accumulation of knowledge, but also in the exclusion of less successful theories and their substitution for better ones. The better theories have greater number of measured consequences. The new method is a critical method and that is why some call it critical rationalism. In essence, this new outlook is a criticism of logical positivism (Russell). It is interesting that Russell praised the early Einstein for his ceasing to remain on the side of positivism, which was manifested in his later papers.

The given approach was, however, abandoned in the past century and a fully phenomenological approach described in the preceding section has been accepted as the only basis of our knowledge. The validity of assumptions involved in individual statements has not been tested. A fundamental gap has existed between theoretical and experimental approach, too; mathematical models have been applied to corresponding experiments without any analyses whether the model assumptions corresponded to given experiments. "Scholars - trying to build theories concerning these inaccessible, directly-non-observable objects, without being able to refer to physical analogies as they did in the past, started to look for laws that have a similar mathematical form to those which appeared and 'worked' earlier. Scholars tried to generalize and even replace with analogous formulas the laws that have a similar mathematical form to those which appeared and 'worked' earlier" (Mrozek 2015, 601). Consequently, the contemporary scientific knowledge contains a series of mistaking basic statements and conclusions (Lokajiček 2007, 657-670).

There is only one possible way to return to true knowledge: going back to the causal ontological approach of classical physics, on which all contemporary technological progress is still based. At the same time, all mistaking concepts and statements are to be corrected. All contemporary scientific results have followed from classical background based on Hamilton equations, in which, at very small velocity values, Newton's simplifying condition (constancy of inertial mass) was always applied to. Hamilton's equations hold, however, in more general case when the experimentally observed inertial mass increase is allowed. The time changes of particle momenta (not velocity changes) are standardly derived from the corresponding potentials with the help of them, which makes it possible to derive corresponding inertial mass increase with rising velocity as it was demonstrated already in Lokajíček and Raus (2010); see corresponding details in sec. 2.2.

The same holds for Schrödinger equation (and any solution corresponding to a superposition of Hamilton equation solutions) when it is rightly interpreted according to the original proposal of Schrödinger on particle basis. We shall try to explain corresponding problems in the following section. We will start by discussing main concepts presently considered and reflecting on the ways how to bring all theoretical interpretations again to agreement with reality. 


\section{MAIN THEORETICAL ALTERNATIVES AND CORRESPONDING PROBLEMS}

At the present, it is commonly accepted that the classical physics holds in the standard macroscopic realm, while in the microscopic realm the quantum physics based on Schrödinger equation is to be used. However, in fact the CQM proposed by Bohr is being applied to, which leads to results that do not correspond to reality. In both (macroscopic and microscopic) realms the special theory of reality that differs fundamentally from classical physics is applied to high velocity values.

\section{Gap between contemporary theory and experimental tests}

On the basis of a phenomenological approach, the corresponding mathematical models that we constructed, describe some sets of measured values in different cases practically without considering any causal relations, i.e. without examining the underlying assumptions that have been used. In principle, nobody was interested whether the given models were in sufficient agreement with corresponding experiments.

Experimental physicists then looked for determining values of free parameters in a given model with maximum possible precision without any analysis of its justification in the given experiment, which may lead to quite false conclusions concerning the reality. For example, in the case of two-proton collisions at high energies, the maximum probability of elastic scattering was attributed to events at zero impact parameter based on unreasoned mathematical relations. It has been said that "theoretical physicists are masters at cutting corners. It is not always certain to what extent are the given arguments valid" (Kotecký 2011, 52). Thankfully, the results of mathematical physicists are not always and immediately accepted by the physics community; however, there are plenty of shortcuts without sufficiently rigorous process of falsification. As of now, no serious interest has been practically devoted to establishing a more detailed structure of colliding particles from the measured data at different collision kinds, either. Practically, no interest has been devoted to the influence of impact parameter value in the corresponding results.

The preceding section considered the main conceptual problems related to our topic of scrutiny. Our main thesis so far highlights the conviction that the whole physical domain - the microscopic and macroscopic realms as well as behaviour at all possible particle velocity values (including the increase of inertial mass) - may be described on the basis of Hamilton equations. Some faulty assumptions have been, however, involved in the currently used physical models, too. We also maintain that these problems should be analysed, and corresponding mistakes removed if we are to extend our knowledge of fundamental reality.

\section{HEIDEGGER'S REFLECTION OF 2OTH CENTURY PHYSICS}

Even before his Turn ('Kehre'), Martin Heidegger [1889-1976] clearly differentiated the role of sciences and its exploration of ontology while never putting them in an 
incommensurable relation. According to him $(1998,27)$, sciences move within "a certain understanding of being." He sees the act of scientifically grasping being as not the only approach of doing it, but rather as one of possible approaches of understanding it. It is about releasing being from implicitness, revealing it. That can be achieved by objectifying it. Being exists even before it has been objectified; becoming an object means answering questions that desire to know the object in connection with its context. According to Heidegger (after the Turn), modern physics after Newton is characterised by invariants. There is a difference between doctrina and scientia, antic $\varepsilon \pi \imath \tau \eta \eta \mu \eta$ [episteme] and modern science. The interpretation of $\tau о \pi \circ \sigma[t o p o s]$ in Galilei's and Aristotle's theory of free fall differ. In modern physics there is no the natural place of the element, as it was in Aristotle's physics.

Max Planck said that reality is that which can be measured. If knowledge resides in measurability, then it is tied to the mathematical nature of physics which "everywhere by means, has set up as the goal of his expectation the harmonizing of all relations of order" (Heidegger 1977, 49). Heidegger understands that modern-day physics implicitly involves a certain degree of unpredictability, as well as, in certain areas, the statistical character of invariants, as opposed to classical physics which deals with material points that exhibit impenetrability similar to that of Democritus' atomistic image of the world. Heidegger also notices physics' attempts to construct a unifying physical theory. The purpose of creating the so-called theory of everything is to envision a single general equation that would become the basis of physics - it is used to postulating such models (for example, the theory of physical vacuum - the theoretical construct of a Russian physicist, Gennady I. Shipov, who attempted to unify physics on the basis of three equations). Whatever branch of physics is dealt with, whether it is general relativity or astrophysics, it always tries to capture being as a certain state which a human being can manage to grasp and utilize for himself by imagining it as an object. Theoretical physics loses its demonstrativeness, but it devises a type of proposition which processes one of the possible propositions for the purposes of objectification using elaborate technical equipment. Heidegger directly mentions the detection of mesons, the GeigerMüller computer, the Wilson chamber. The attempt of theoretical physics at processing reality has a purpose which constitutes the unyielding endeavour of people to imagine it as an object. "Every new phenomenon emerging within an area of science is refined to such a point that it fits into the normative objective coherence of the theory" (Heidegger 1977, 48). A scientist thus struggles to view being as in image. That is the purpose of theory as well as empirical research. What Heidegger $(2002,48)$ notices critically, however, is that not only the natural world around humans is objectified in this way but also human beings themselves become "transparent objects capable of being mastered by calculation." So progress in our supposed mastery over nature and each other may instead be viewed as "an impotence of will" (Heidegger 2002, 25) that avoids certain aspects of that which it seeks to comprehend.

Carnap (1959) responds to Heidegger especially in his "The Elimination of Metaphysics through Logical Analysis of Language" (originally published in 1932). The philosophical congress in Davos in 1929 became a stimulus, where Carnap listened 
to Heidegger's lectures on Kant. His criticism is not a targeted refutation of his postulates, but rather it is the basic falsification of his method and the vocabulary that Carnap considers to be wrong from the ground up. The message of the reaction is that Heidegger and his epigones are engaging in philosophy in the wrong way (Sousedik 2005, 198). Some words in the metaphysical texts, according to Carnap, have no meaning. The second mistake is their mismatch within the logical syntax of the language. The construction of the sentence must not contradict the logical syntax. Carnap's criticism is mainly focused on Heidegger's (1983) lecture "What is Metaphysics?" [Einführung in die Metaphysik - originally published in 1953]. He considered it wrong and contradictory to logic that Heidegger used the term 'nothing' as an object name. Overall, Heidegger's text appears to Carnap as contradictory to logical principles. He concludes that the nonsensical sentences of metaphysics serve to express life feelings. According to Carnap $(1959,69)$, the character of natural language is to blame. "The fault of our languages, identified here, lies, therefore, in the circumstance, in contrast to a logically correct language, it admits of the same grammatical form for meaningful and meaningless word sequences."

One can take an issue with Carnap that, though he is talking about empirical reductionism on protocolary sentences, he never defined them satisfactorily (Sousedik 2005, 206). Against Carnap's conclusion that Heidegger's metaphysics is merely a misrepresentation of his life attitude, it can be argued that Carnap's attitude is excessive radical.

Heidegger himself reacted to Carnap's criticism twice. His first remark is in an unpublished sketch of a university introduction to metaphysics, where Heidegger writes that, in a strictly logical language, metaphysical sentences become impossible. He considers it to be the fulfilment of the most sophisticated doctrine of logical judgment. Heidegger $(1983,227-228)$ says that "the final consequences of thinking, started with Descartes, are being brought to an end, for which truth is no longer a manifestation of existence." Heidegger considers Carnap's criticism in the article in question to be the pinnacle of reducing the meaning of being, in its derivation from the verbal form "is," namely, reducing the existence to an existential quantifier. There is also a very short indirect reaction in the afterword of the lecture "What is Metaphysics?": "Such a 'philosophy of mere feelings' endangers 'exact' thinking and the certainty of action" (Heidegger 1998, 233). Here Heidegger points out provocatively to Carnap's reproach that metaphysical sentences are merely the meaning of artistic phrases that express a living feeling. He thinks that Carnap understands logic based on the positions of immanent reasoning. In contrast, Heidegger considered the origin of logic in ancient times to be wider. In addition, Heidegger considers countability to be a potentially dangerous manipulability.

\section{CONCLUSION}

In the last century, the phenomenological approach pushed the classical, causalontological approach fully away. The goal of physical theory consisted of formulating 
mathematical models that were able to describe a set of measured values without testing the assumptions the given models were based on; neither was their agreement with corresponding experiments tested.

We argue that true scientific progress has been seriously impaired because of such faulty approach. We remain convinced, as was shown in the preceding paragraphs, that Hamilton equations may represent the theoretical basis of GCP (generalized classical physics, involving the increase of inertial mass with velocity), which may then be applied to the whole physical reality. The same holds for Schrödinger equation solutions that always represent the superpositions of individual solutions of Hamilton equations, if they are interpreted on particle basis. We have not articulated any preference for a specific version of the special theory of relativity. Classical interpretations of quantum mechanics (Bohm) seem to be clearer and closer to the truth than Copenhagen's interpretation influenced by Positivism.

The best way forward in the future, therefore, consists in returning to the classical, causal ontological approach where Newton's earlier simplifying condition (concerning the constancy of inertial mass) will not be applied to. At the same time, all mistaking assumptions discussed in the preceding sections are to be removed. It is absolutely necessary to examine again all possible consequences of unarticulated assumptions established on the basis of logical induction and to exclude falsified assumptions from further considerations.

Philosophy is not dead. On the contrary, philosophy can steer us in a proper direction and help us return to the classical, causal-ontological approach (Kralik and Tinley 2017, 25-29). To do this, we must first abandon the approach characteristic of Auguste Comte, Ernst Mach and other representatives of the Vienna Circle. Above all, we criticize the focus put exclusively on phenomena, which primarily influenced physics in the broad application of the phenomenological approach. The most influential logical positivist in the 20th century was Rudolf Carnap, who, in later years, himself discounted pre-accepted positivism. Nevertheless, he never gave up the position of the phenomenological approach. There is a ready philosophical resource available for us, as the phenomenological approach was criticised also by the second wave of analytical philosophy (Quine, Rorty, Davidson, etc.). The philosophy of Positivism as a specifically reductionist paradigm strongly influenced science mainly in the first half of the 20th century. Comte influenced Planck and the positivists influenced Bohr as well as young Einstein. The voice of strict positivism is getting weaker in contemporary philosophy, which should be seen as a positive development. A good example of this is a recent interpretation of the religious impact of Wittgenstein's Tractatus Logico-Philosophicus written by Bojan Žalec $(2016,457-470)$.

This positive trend, however, should in no way diminish our efforts to pose critical questions regarding the fundamental (or initial) presuppositions stemming from a certain metanarrative framework of each thinking subject, in our case, natural scientist. As David Bentley Hart $(2013,293)$ correctly observes:

Regarding the ultimate nature of reality, at least, neither the general 
consensus of a culture nor the special consensus of a credentialed class should be trusted too readily, especially if it cannot justify itself except by reference to its own unexamined presuppositions. So much of what we imagine to be the testimony of reason or the clear and unequivocal evidence of our senses is really only an interpretive reflex, determined by mental habits impressed in us by an intellectual and cultural history. Even our notion of what might constitute a 'rational' or 'realistic' view of things is largely a product not of a dispassionate attention to facts, but of an ideological legacy.

Each rational agent, that is, every scientist, is influenced by their own framework of thinking (metanarrative framework), within which they exercise their epistemological activities, which then shapes much of their scientific methodology, scope, and general character of intellectual inquiry. Kuhn warns scientists not to allow themselves to be locked in prevalent and/or fashionable scientific paradigms that can prevent them from being consistent as scientists in falsifying their theories, reverting instead to stubbornly defending that which is taken for granted by their scientific community (Kuhn 1970, 9495).

Philosophy of science should be regarded as an important, even indispensable element of human scientific endeavours. As philosophers we must unceasingly call attention to the fact that by holding a priori assumptions (based on our metanarrative framework) which we then superimpose on the data, we are bound to arrive at conditioned, incomplete results in widely divergent understandings of meaning. For example, if we assume that all sensory data is normatively and objectively perceived and/or the validity of "the principle of uniformity," as part of your methodology, it will dramatically alter our interpretation or reality. It would be unhelpful and illegitimate to claim that these assumptions are wrong; we should rather recognize and openly admit that they are assumptions and need to be acknowledged as such and argued for to be accepted. This is something that the Logical Positivists and many contemporary scientists refuse to do (Valčo 2017, 28). Even our most cherished certitudes can never be truly separated from "our own personal experiences," which means that we are in a situation of having "an original inclination of the mind toward reality from a certain perspective" (Hart 2013, 294). It is both sobering and humbling to realize with full seriousness that neither science nor philosophy can guarantee our ability to "sort out the valid preconceptions from the invalid, as every form of philosophical thought is itself dependent upon a set of irreducible and unprovable assumptions" (Hart 2013, 294). This "epistemological modesty" should in turn lead us to intellectual humility and openness to other perspectives on reality, including any potentially unsettling interpretations of human experience, while always striving to meticulously examine our fundamental presuppositions, operative frameworks and paradigms.

* This paper was supported with institutional grant IG-KSV-01/2016-2.1.5. 


\section{RE F E R E N C E S}

Avenarius, Richard. 1890. Kritik der reinen Erfahrung von Dr. Richard Avenarius. Vol. 2. Leipzig: Fues.

Barrow, John D. 2000. Đ in the sky. Translated by Natalie Stehlíková. Praha: Mladá fronta.

Bitbol, Michael. 1995. Schrödinger's philosophy of quantum mechanics. Dordrecht: Kluwer Academic Publishers.

Bohr, Niels. 1925. Über die Wirkung von Atomen bei Stössen. Zeitschrift für Physik 34(1): 142-157.DOI: 10.1007/BF01328464 $121,580-591$.

1928. The quantum postulate and the development of atomic theory. Nature

Bukovský, Lev. 2011. The structure of the real line. Basel: Springer.

Carnap, Rudolf. 1932. Über Protokollarsätze. Erkenntnis 3(1): 215-228, DOI: 10.1007/ BF01886421

1934a. Logische Syntax der Sprache. Vienna: Springer.

1934b. On the character of philosophical problems. Philosophy of science

$1,5-19$

1936. Testability and meaning. Philosophy of Science 3, 419-471.

1939. Foundations of logic and mathematics. In International Encyclopedia of Unified Science, Vol. 1 (3). Chicago, Illinois: The University of Chicago Press.

. 1945. The two concepts of probability: The problem of probability.

Philosophy and phenomenological research 5(4): 513-532.

. 1950. Empiricism, semantics and ontology. Revue Internationale de

Philosophie 4, 20-40.

.1959. The elimination of metaphysics through logical analysis of language.

In A. J. Ayer, Logical positivism. London: Allen \& Unwin, pp. 60-81. . 1963. Intellectual autobiography. In The philosophy of Rudolf Carnap.

Edited by Paul A. Schilpp. Illinois: Northwestern University La Salle, pp. 1-84.

Comte, August. 1868. The positive philosophy of Auguste Comte. 1st ed. New York: W. Gowans.

Crumpei, Gabriel, Alina Gavrilut, Gabriel Gavrilut. 2016. The mathematics of axiomatics systems in the cognitive perception of reality. In 3rd International Multidisciplinary Scientific Conference on Social Sciences \& Arts SGEM 2016. Sofia: SGEM, pp. 789798.

Dolidze, Mamuka. 1999. The phenomenological conception of quantum theory and the polyphony of modern fiction. Analecta Husserliana 60, 113-128. DOI: 10:1007/97894-017-2083-0

Fiala, Jiř́. 2006. Analytická filosofie - Úvod. Plzeò - Nymburk: O.P.S.

Fraenkel, Abraham. 1921. Uber die Zermelosche Begründung der Mengenlehre. Jahresbericht der Deutschen Mathematiker-Vereinigung 30(2) 45-46.

Grygar, Filip. 2014. Complementary thinking of Niels Bohr in the context of physics, Philosophy and Biology. 1 st ed. Červený Kostelec: Pavel Mervart. 
Hahn, Hans, Otto Neurath, RudolfCarnap. 1973. The scientific conception of the world: The Vienna circle. In Empiricism and sociology. Edited by M. Neuratt and R. S. Cohen. Dordrecht: Springer, 299-318.

Hart, David B. 2013. The experience of God: Being, consciousness, bliss. New HavenLondon: Yale University Press.

Heidegger, Martin. 1983. Einführung in die Metaphysik. Gesamtausgabe: Abt. 2, Vorlesungen 1923-1944. Frankfurt am Main: Klostermann. . 1998. Postscript to what Is metaphysics? In Pathmarks. Martin Heidegger. Cambridge: Cambridge University Press, pp. 231-238. .1977. The question concerning technology and other essays. 1st ed. Harper \& Row: New York. 2002. Off the beaten track. Edited and translated by J. Young and K. Haynes. Cambridge: Cambridge University Press.

Heisenberg, Werner. 1978. Physik und Philosophie. 3rd ed. Stuttgart: Hirzel.

Hilbert, David and Wilhelm Ackermann. 1928. Grundzüge der theoretischen Logik [Principles of Mathematical Logic]. Berlin: Springer-Verlag.

Hintikka, Jaako. 1996. Wittgenstein and language as the universal medium. In Lingua Universalis vs. Calculus Ratiocinator. Jaako Hintikka. Dordrecht: Springer, pp. 162190.

Hoyer, Ulrich. 2002. Synthetische Quantentheorie. 1st ed. Hildesheim: Georg Olms Verlag. Hymers, Michael. 2005. Going around the Vienna circle: Wittgenstein and verification. Philosophical Investigations 28, 205-234. DOI: 10.1111/j.1467-9205.2005.00254.x

Ioannidou, Helene. 1982. A new derivation of Schrödinger equation. Lett. al Nuovo Cim. 34,453-458. DOI: $10.1007 / B F 02754885$

Jelen, Josef. 2018. O interpretaci kvantové mechaniky. [online] Available at: https:// aldebaran.feld.cvut.cz/vyuka/moderni_fyzika_pro_kybernetiku/clanky/ kvantmech.pdf. (cit. 11 Jan 2018)

Karaba, Miroslav. 2009. Filozofické implikácie kvantovej teórie vo filozofii prírody. 1st ed. Trnava: Dobrá kniha.

Kotecký, Roman. 2011. Na rozhraní medzi matematikou a fyzikou. In Spor o matematizaci světa. Edited by P. Kùrka, A. Matoušek and B. Velický. Červený Kostelec: Pavel Mervart, pp. 45-54.

Kralik, Roman and Susanne J. Tinley. 2017. Kierkegaard's ethics as an answer to human alienation in technocratic society. Communications - Scientific Letters of the University of Zilina 19(1) 25-29.

Kuhn, Thomas S. 1970. The structure of scientific revolutions. 2nd ed. Chicago: University of Chicago Press.

Lokajíček, Miloš V. 2007. Schrödinger equation, classical physics and Copenhagen quantum mechanics. New Advances in Physics 1, 69-77.

.2007. Phenomenological and ontological models in natural science. Concepts of Physics 4, 657-670.

Lokajíček, Miloš V. and Jaroslav Raus. 2010. Is the mass increase with velocity classical 
phenomenon? [online] Available at: arXiv:1110.2771v1[physics.gen-ph] (cit. 11 Jan 2018)

Mach, Ernst, Sidney Waterlow, and Thomas Szasz. 1959. The analysis of sensations and the relation of the physical to the psychical. New York: Dover Publications.

Mach,Štěpán. 2009. Inductive logic and the Vienna circle. Praha: Charles University.

Maco, Robert. 2018. Philosophy is dead. Long Live Physics!. Filozofia 73, 269-281

Mihina, František. 2006. Rudolf Carnap. In Logický pozitivizmus. Bratislava: Iris, pp. 247-256.

71,680-695.

2016. Moritz Schlick, the Vienna scientism and new philosophy. Filozofia

Mrozek, Jaroslav. 2015. Is there retreat from naturalism to physics?. In 2nd International Multidisciplinary Scientific Conference on Social Sciences \& Arts SGEM 2015. Sofia: SGEM,pp.599-606.

Planck, Max. 1991. Vom Wesen der Willensfreiheit Und Andere Vorträge. 2nd ed. Frankfurt: Fischer.

Rorty, Rirchard. 1979. Philosophy and the mirror of nature. 1st ed. New Jersey: Princeton University Press.

Schlick, Moritz. 1948. Positivism and realism. Synthese 7, 466-477.

Schmelzer, Ilja. 2015. The paleoclassical interpretation of quantum theory. Horizons in World Physics 284, 179-211.

Schmidt, Martin. 2010. Objects, causation and scientific realism. Filozofia 65, 643-651.

Schuster, Radek. 2011. Wittgenstein and the origin of perfectionism. In Studie kfilosofii L. Wittgensteina. Edited by L. Dostálová. Praha: FF ČAV, pp. 113-134.

Sousedík, Prokop. 2005. Carnapùv pokus o kritiku Heideggerovy metafyziky Dva póly evropské filosofie 20. Století. In Schizma filozofie 20. století. Praha: Filosofia, pp. 195-216.

Sucharek, Pavol. 2006. Through the tourniquet of Levinas's time. Filozofia 61, 642-658.

Svečnikov, Gennadij I. 1966. Kategorie prièinnosti ve fyzice. 1st ed. Praha: Svoboda.

Tondl, Ladislav. 1968. Pøedmluva. In Problémy jazyka vědy. Rudolf Carnap. Praha: Svoboda.

Turing, Alan M. 1938. On computable numbers, with an application to the Entscheidungsproblem. A correction. Proceedings of the London Mathematical Society 2(1) 544-546.

Valčo, Michal. 2017. Combating scientism - Lessons from David Bentley Hart and Charles Taylor. In Ethical aspects of contemporary scientific research. Edited by Michal Valco and Peter Konya. Ljubljana: KUD Apokalipsa, 14-35.

Viceník, Jozef. 1999. Teória falzifikácie K. R. Poppera a exaktnos. Organon F 6, 158-166.

Volek, Peter. 2011. Objects as substances. Filozofia 66, 367-373.

Whitney, Cynthia K. 2015. Old math and renewed physics: Key to understanding gravity. In Advances in general relativity research. Edited by C. Williams. New York: Nova Publishers, pp. 61-80.

Žalec, Bojan. 2016. Wittgenstein and faith: From showing of the mystical notion of theology as grammar. Theological Quarterly 76(3-4), 457-470. 
Zermelo, Ernst. 1908. Untersuchungen über die Grundlagen der Mengenlehre. Mathematische Annalen 65(2) 261-281.

Zouhar, Marian. 2004. Vznikla analytická filozofia?. Organon F 4, 202-207.

Submitted: 8 November 2018; revised: 7 May 2019 